\title{
Prosthetic rehabilitation using adhesive bridge and fixed-fixed bridge on the maxilla and telescopic crown overdenture on mandible
}

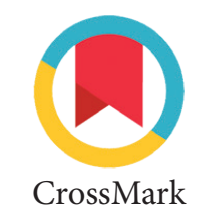

Indah Sulistiawaty, ${ }^{1 *}$ Mohammad Dharmautama, ${ }^{2}$ Edy Machmud, ${ }^{2}$ Jevin S. Cialy, ${ }^{1}$ Elvi ${ }^{1}$

\section{Abstract}

Objective: Prosthetic rehabilitation is the rehabilitation process of masticatory and esthetics function for patients missing teeth and alveolar bone by means of manufacture and installation of dentures. The prosthetic rehabilitation commonly used include denture adhesive bridge, fixed-fixed bridge, as well as telescopic overdenture. The aim of this study is to expose the procedures of prosthetic rehabilitation using adhesive bridge and fixed-fixed bridge on the maxilla and telescopic crown overdenture on mandible.

Methods: Male patients aged 32 years came with complaints of difficulty to chew food because he had lost some teeth behind. In the maxilla, teeth are lost in the region of 15 and 16 performed by making the fixed-fixed bridge with abutment teeth 14 and 17. Loss of teeth in the region of 26 , performed the manufacture of adhesive bridge with a box preparation on the occlusal 25 and 27.

Results: In the mandible, tooth loss in the region of $36,37,46$ and 47 performed manufacture of telescopic crown overdenture with primer coping on the teeth 35, 38, 45 and 48 and the secondary coping on a metal frame.

Conclusion: Prosthetic rehabilitation especially in the case of loss of back teeth is very important because with the denture patients can chew properly and maintain the stomatognathic system.
${ }^{1}$ Faculty of Dentistry, Hasanuddin University

${ }^{2}$ Departmen of Prostodontic, Faculty of Dentistry, Hasanuddin University, Makassar, Indonesia

*Correspondence to: Indah Sulistiawaty, Faculty of Dentistry, Hasanuddin University indah_mar507@yahoo.com

Received: 09 0ctober 2016 Revised: 15 November 2016 Accepted: 22 November 2016 Available online: 18 December 2016

Keywords: Adhesive bridge, Fxed-fixed bridge, Telescopic crown

Cite this Article: Sulistiawaty I, Dharmautama M, Machmud E, Cialy JS, Elvi. 2016. Prosthetic rehabilitation using adhesive bridge and fixed-fixed bridge on the maxilla and telescopic crown overdenture on mandible. Journal of Dentomaxillofacial Science 1(3): 210-212. D0I: 10.15562/ jdmfs.v1i3.320

\section{Introduction}

In the development of this modern age, dental care enables a dentist performs restoration and attempt to keep the natural teeth for the interest as the abutment. Conventionally, tooth-supported denture covers bridge denture, a combination of fixed and removable dentures, partial removable denture and overdenture. The use of denture purposes not only to improve the function of mastication, phonetic function and aesthetic function, but also need to maintain the health of the rest of the tissues. For this latter purpose besides closely related to the maintenance of oral hygiene, as well as how to set up the forces that occur are still functional or reduce the number of force that is likely to be damaging. ${ }^{1}$

The magnitude and direction of the partial removable denture movement for functioning were influenced by the natural supporting structure and the denture design. Functional styles will be distributed to the supporting teeth through the occlusal cradle, the guiding plane and the direct retainer. An optimal design can maintain abutment health and the supporting tissue. Errors in designing the grip can cause uncontrolled load distribution gear to abutment and other supporting tissues. ${ }^{1}$
Telescopic crown denture overdenture is denture using a double crown, which consists of coping and a removable denture on it. The principle of the telescopic crown system is composed of two elements, namely internal crown called the primary crown and the external crown called the female or secondary crown. So using telescopic denture can provide protection for an abutment, lighten the load received by abutment and provide a more aesthetic result. Telescopic denture is a modified form of existing conventional denture and overdenture with profits increasing retention, rigid vertical support, stability and proprioception..$^{2,3}$

At the bridge denture, the magnitude and direction of denture movement are more stable so that the occlusion force applied to the periodontium tissues and alveolar bone near normal. Denture bridge commonly used is adhesive bridge and fixedfixed bridge. Adhesive bridge is a bridge denture consisting of single pontic and two retainer wings attached to the abutment using cement or resin. The retention is in the form of micromechanic between the enamel surface and the retainer surface. The denture has a very minimal preparation so that it is more conservative. While fixed-fixed bridge is a 
bridge denture that has two or more abutment with rigid connectors on both ends of the pontics. This denture gave strength and excellent stability and also distributed pressure more evenly to the restoration and providing an excellent splinting effect. ${ }^{4,5}$

In this paper, it would be reported about manufacture of telescopic crown overdenture on the mandible and the adhesive bridge and fixed-fixed bridge in the maxilla that serves to repair and restore the mastication of the patients.

\section{Case Report}

A male patient with aged 32 years old came to the Dental Hospital Hasanuddin University with complaint that it is difficult for him to chew food because he had lost teeth in the maxilla and mandible. Patient's general condition is good and there is no systemic disorder. It could be seen from intraoral examination that the missing teeth are $15,16,26,36,37,46$ and 47 figure 1 . Teeth 17 , 27, 38 and 48 mesioversi. Radiographs showed no presence of radiolucent and crown root ratio of $1: 2$ figure 2.

The treatment carried out in this case is the manufacture of adhesive bridge on tooth 25-0-27 and fixed-fixed bridge on 14-0-0-17 for maxilla, while the on the mandible performed
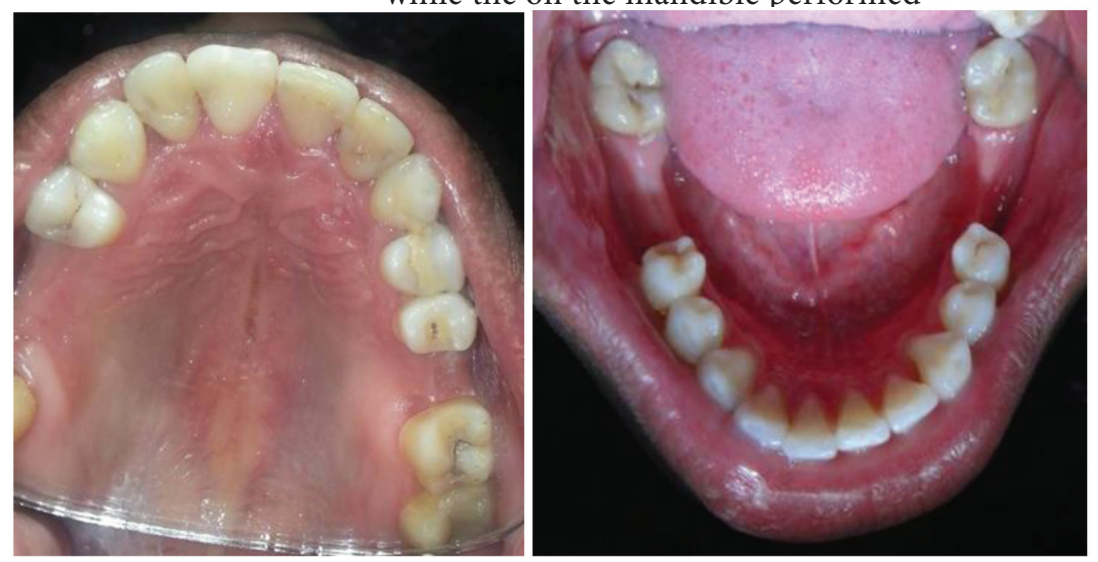

Figure 1 Overview of intraoral maxilla and mandibleprior to the manufacture of dentures

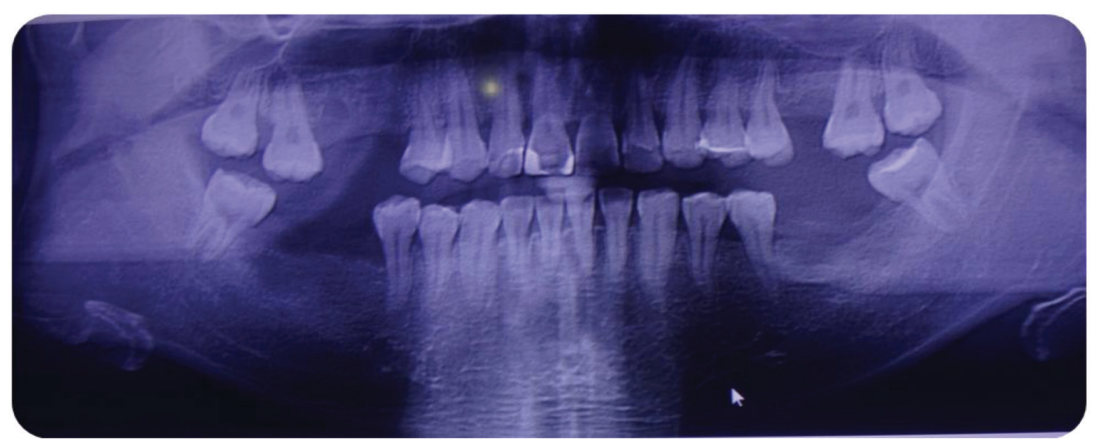

manufacture of telescopic crown overdenture on tooth $35,38,45$ and 48 . In the early stages performed printing for manufacture of diagnostic model and manufacture of temporary denture. Preparation was performed in boxshaped on the occlusal teeth 25 and 27 for the manufacture of adhesive bridge and preparation of 14 and 17 for the manufacture of fixed-fixed bridge, followed by a double impression printing, the determination of the bite and the lab process. Adhesive bridge and fixed-fixed bridge that were completed in insertion figure 3 , were continued with the preparation of $35,38,45$ and 48 for the manufacture of a primer coping on teleskopic crown overdenture. Furthermore, printed with elastomer printed material in the maxilla and mandible to obtain a working model. Primary crown of the teeth $35,38,45$ and 48 were made in advance and performed cementation; and perform reprint in the mandible to obtain a working model for the manufacture of the secondary crown that will blend with the metal frame dentures. Before the implementation of the laboratory work of manufacture of denture metal frame, it must first be obtained occlusion relationship between the maxilla and mandible by making biting bunds in the maxilla and mandible, followed by noting the bite of the maxilla and mandible. After that, performed the metal frame try-in, teeth posterior try-in, the lab process and then installation of the mandibular denture figure 4 .

\section{Discussion}

Loss of teeth, especially the posterior teeth can cause disharmony in the oral cavity. Antagonist teeth and neighboring teeth may experience pathological migration resulting in decreased in efficiency of chewing, and disorders of the TMJ. To overcome this required a prosthesis to restore normal occlusion. Prostheses used may be removable prosthesis and fixed prosthesis. ${ }^{2}$

Adhesive bridge is a bridge that has pontic and retainer of thin metal attached to the abutment proximal and lingual/palatal by means of adhesive material and using the acid etching technique. Because retention obtained from the adhesive material so that bridge adhesive is also called with the name of resin bonded fixed prosthesis. In this case we used the adhesive bridge to replace the lost teeth of 26 with consideration that edentolous ridge in the region of 26 has been narrowed to distal mesio width of approximately half of the distal mesio width of the first molars and has a sturdy abutment

Figure 2 Panoramic photo prior to the manufacture of dentures 


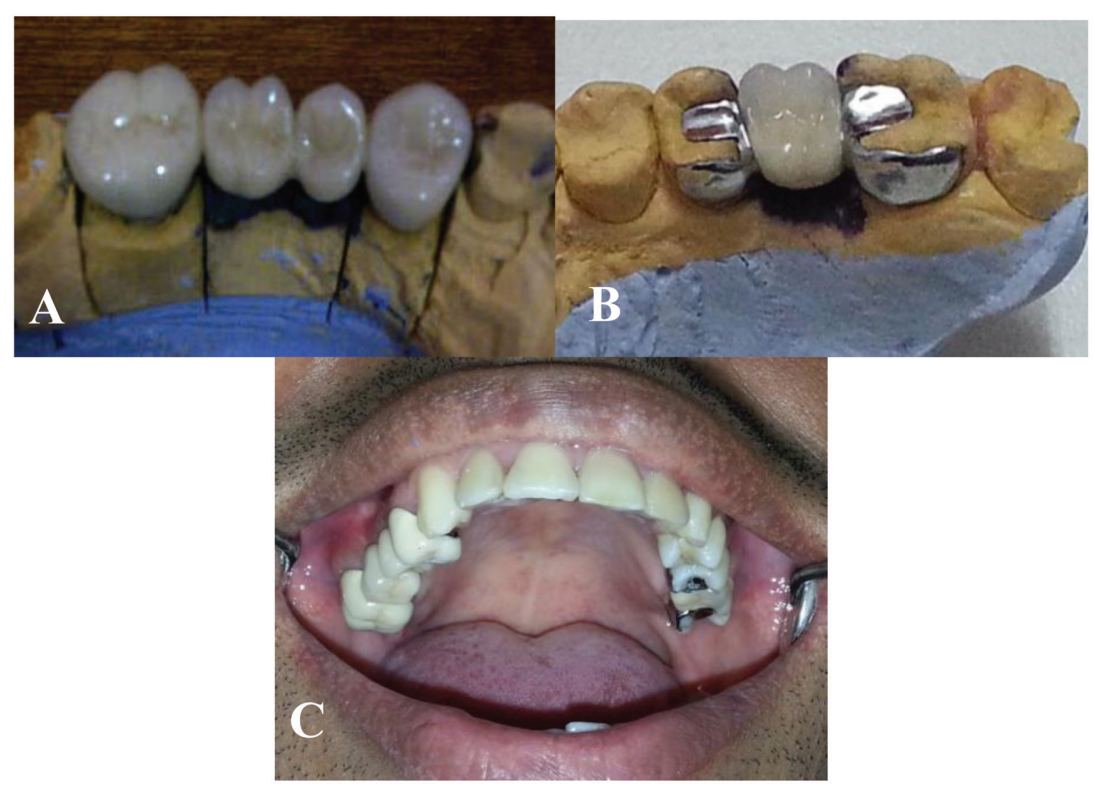

Figure 3 A. Fixed-fixed bridge, B. Adhesif bridge, C. Insertion of fixed-fixed bridge and adhesive bridge in maxilla

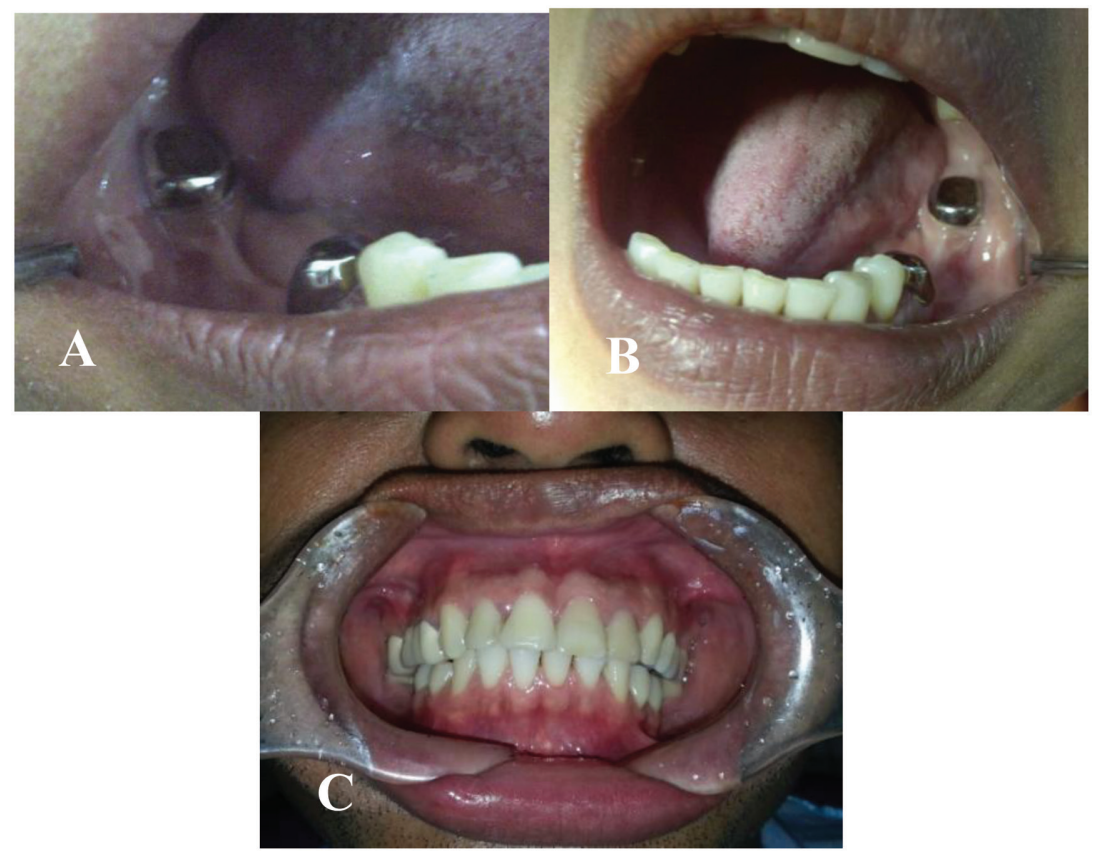

Figure 4 Primary coping insertion of teeth 45 and 48, B. Primary coping insertion of teeth 35 and 38, C. Teleskopic crown overdenture insertion in mandible

and good arrangement. Another advantage of the adhesive bridge was the minimal preparation and did not involve dentin so that the sensitivity and abutment trauma can be reduced. $^{5}$
Correction for the loss of teeth 15 and 16 was by manufacturing fixed fixed bridge 4 units. Fixed fixed bridge is a fixed denture using rigid connectors on both ends of the pontic. The dentures were attached using resin cement. The dentures cannot be removed by the patient except by the doctor. Compared with removable denture, fixed denture has several advantages such as convenient like the original teeth, does not take long for adaptation but requires diligence in the cleaning. Minimum once in 6 months the patient has to go to the dentist to control plaque and calculus. ${ }^{4,5}$

Correction of the loss of the teeth $36,37,46$ and 47 were established of telescopic crown overdenture. Telescopic crown overdenture is denture composed of two kinds of coping, that is, primary coping that will be attached permanently to the abutment and secondary coping attached to the denture frame. The advantage of a telescopic crown overdenture is that there is more equitable chewing burden sharing so that it can minimize bone resorption and the proprioceptive effect obtained from the abutments. Therefore in this case we used a telescopic prosthesis. ${ }^{2}$

\section{Conclusion}

Prosthetic rehabilitation especially in the case of loss of back teeth is very important because with the denture patients can chew properly and maintain the stomatognathic system.

\section{References}

1. Ardan R. Disain gigi tiruan sebagian lepasan frame: kasus berujung bebas. Bandung: Makalah seminar nasional Peril IKG; 2007.

2. Sutanto D. Distribusi beban kunyah cangkolan RPI dan RPL pada kasus gigi tiruan berujung bebas rahang bawah dengan metoda fotoelastik. Bandung: Program pendidikan Dokter Gigi Spesialis Prosthodontik, Fakultas Kedokteran Gigi Universitas Padjajaran; 2007.

3. Gurbulak, Deger S. Photoelastic stress analysis of distal exstension removable partial telescopic denture with different conical crown. Available: http://sagens.erciyes.edu.tr//dergi/ 2009_2/aysegulgurbulak.pdf. Diakses 25 September 2010.

4. Rosenstiel SF, Land MF, Fujimoto J. Contemporary fixed prosthodontics. 4th ed. Missouri: Mosby Elsevier; 2006. p. 805-24.

5. Smith, Bernard GN, Howe, et al. Planning and making crown and bridges, 4th ed. New York: Informa Health care; 2007.

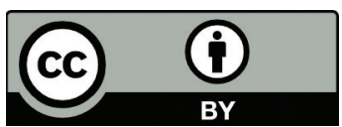

This work is licensed under a Creative Commons Attribution 